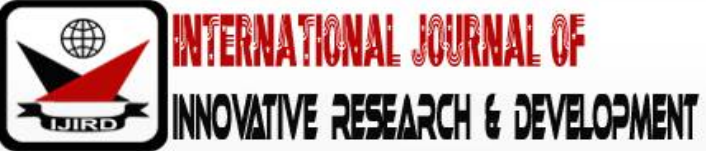

ISSN 2278 - 0211 (Online)

\section{Can Gold Provide a Hedge against Inflation and Exchange Rate Movements in Ghana?}

\begin{tabular}{c} 
Abubakari Najimu \\
Assistant Registrar, Department of Academic Affairs Directorate, \\
Tamale Technical University, Ghana, Tamale \\
Marvin Senanu Akyea \\
Assistant Registrar, Department of Academic Affairs Directorate, \\
Tamale Technical University, Ghana, Tamale \\
\hline
\end{tabular}

\begin{abstract}
:
In this work, we examined whether gold can provide a safe haven against inflation and exchange rate movement in Ghana using data spanning 1990-2012. We employed the regression model. Our findings reveal that, gold serves as both a perfect and imperfect hedge against inflation. For exchange rate, the findings suggest that gold is able to perfectly hedge against any exchange rate movement. This shows that in the event of any inflation or currency depreciation, gold investors tend to benefit more because gold hedges them against these risks. The study also discusses some policy implications which encourages investors to invest more in gold as it is able to serve as a hedge against inflation and exchange rate movement when held for a long period of time. Same cannot be said for gold hedging against inflation and exchange rate movement.
\end{abstract}

Keywords: Gold, Investor hedge, exchange rate and inflation

\section{Introduction}

\subsection{Background}

Inflation and exchange rate play a major role in the economic growth of a country. The impact of inflation and exchange rate on an economy can either be positive or negative. Inflation is defined as the persistent rise in the price of goods and services in an economy over a given period of time. When inflation occurs, it lowers the purchasing power, the cost of living of people and the real income of an economy. However, Vincent Tie defines inflations as the expansion of the supply of money in an economy. This results in having more currency competing for the same amount of goods and services thus pushing up prices. Generally, economists are of the view that the high inflation rates are as a cause of the excess or increase growth in the supply of money in a country. The stock exchange market refers to the place where shares of public listed companies are traded. Exchange rate refers to the value of one currency against another. The exchange rate of a country affects its economy and the life of people in the country. The rise and fall in exchange rate are termed as exchange rate volatility. When the Ghana cedi rise in its value foreign goods becomes cheaper for Ghanaians to purchase. Hence, products made in Ghana becomes more expensive for foreigners. In the same way, a depreciation in the cedi makes made in Ghana products cheap to foreigners and their goods becomes expensive for Ghanaians to purchase. Some factors which influence a country's exchange rate are inflation, interest rate, and many others. In the case of Ghana, exchange rate mostly depreciates and is seen by foreign investors as of no value. Gold as an investment over the years has become very important for investors. It is one of the most valued mineral resources among the precious stones and is respected for its rich nature around the globe. Gold has been in existence for a very long period of time; however, it has been able to maintain its value over time. Gold may not be the most liquid of the assets but it is definitely superior to other commodities on this respect.

According to Vuyyuri and Mani (2005), a liquid asset is an asset which can be converted into cash and gold is considered a liquid asset because it can be sold in terms of commodity at the exchange market and can be converted into cash. Among the various precious stones, gold is promoted mostly as an investment and is viewed as the most effective metal with hedging and safe haven properties across various countries. Investors buy gold for reasons such as hedge against inflation and currency crises that may arise in the future. Studies has shown that, higher inflation results in higher interest rate which leads to increase in the exchange rate. Moreover, research has proved that as gold increases, inflation increases and as such exchange rate also increases. Gold has historically been an excellent hedge against inflation because its price tends to rise when the cost living increases. Over the past fifty years, investors have seen gold prices soar and stock market plunge during high inflation years (DALTORIOS, 2008). Gold may be an inflation hedge in the long-run but it is also characterized by significant price short-run volatility moving independently of paper investments' (Aggarwal, 
1992). Research conducted by (Ghost et al, 2004) reveals that, people buy gold and use as investment with the idea that it provides a hedge against inflation and exchange rate. Generally high inflation and exchange rate movement is not very good since it actually disrupts planning, therefore for a developing country like Ghana, there is a need to determine the hedging capacity of gold against inflation and exchange rate to contribute to the economic growth.

\subsection{Problem Statement}

This issue of high inflation and exchange rate volatility has been a real interest to both local and foreign investor and the growth of an economy as a whole around the globe. The study on whether gold can provide a safe haven to inflation and exchange rate has become of great importance to many countries, however very few studies have been done concerning this topic. Even with the few studies made most of them relate to developed countries such as the United States of American and Great Britain. For an Asian continent like India a developing country, a study conducted by Seshaiah et al (2003) revealed that returns on gold have proved to be a prefect hedge against inflation. Chua and Woodward (1982) McDonald and Solnik (1977) have all made studies relating to a developed country such as the US. Proving that gold serves as a hedge against inflation and exchange rate movement. However, for a developing economy such as Ghana, there has been little study on the topic. Ibrahim and Musah (2015) conducted a research on the study for Ghana, relying on data spanning 1990-2012 revealing that gold provides an imperfect hedge against inflation and exchange rate. Therefore, in the case of Ghana, it has become difficult proving whether gold actually serves as a hedge for inflation and exchange rate since very few studies that has been made. Moreover, with the findings which have been discovered over the years around the globe, there are some which are of the view that gold provides a safe haven only in the long run. Therefore, the study on whether gold can serve as a safe haven against inflation and exchange rate movement in Ghana still requires more research attention. The exchange rate movement and inflation are two major economic issues that affect the growth of the Ghanaian economy. An investor will invest in an economy where it is safe for him to make adequate profit or where in the event of any form of risk, he can be hedged. Although very few studies have been made on this topic, this study seeks to examine the hedging capacity of gold against inflation and exchange rate and also provide clarity on the study. The study will therefore enable us to clarify whether gold can provide a safe haven inflation and exchange rate movement in Ghana.

\subsection{Research Objectives}

The general objective of this study is to determine whether gold can serve as a hedge to provide a safe haven against inflation and exchange rate in Ghana. Specifically, this study aims at;

- To document the empirical distribution on the trend of gold returns, inflation and exchange rate behavior in Ghana.

- To determine the hedging capacity of gold against inflationary pressures in Ghana.

- To examine the hedging capacity of gold against exchange rate movement in Ghana.

\subsection{Justification of the Study}

The significance of this study will help improve in the economic growth of Ghana. Although a lot of studies have been made on the topic, very few of them relate to Ghana. This research will contribute a lot more to the topic whether gold can serve as a safe haven against inflation and exchange rate on the short term or on the long term in Ghana. The study will provide more information on the hedging capacity of gold in developing economy like Ghana. The findings from this research will also enable investors decide on how to invest in Ghana and plan for their activities. Again, this study seeks to provide more concourse finding to the study, whether gold serve as a safe haven or a direct investment for making profit, the study will provide more information thereby enabling investors decide on the kind decision they make. This study will enable investors, government, businesses and citizens in the country on how to invest.

In all this study will be added to the existing materials or the topic 'can gold provide a safe haven against inflation and exchange rate movement in Ghana'

\section{Literature Review}

\subsection{Introduction}

This chapter reviews some of the existing literature and works done by various researchers on Gold serving as a hedge against inflation and exchange rate. It also highlights the econometrics models used in arriving at various conclusions. This chapter also takes a look at the Ghana Stock exchange market and the trend of gold returns.

\subsection{Stylized Fact about Gold Serving as a Hedge against Inflation and Exchange Rate Movement in Ghana}

Gold is precious metal that has been in existence and use over a very long period of time, and has been able to maintain its value over these years. Two uses of gold have been identified by Ghosh et al. (2004) as the 'use demand 'and the 'asset demand'. The use demand serves the purpose of making jewelry, medals, coins, etc. and the 'asset demand' is used by individuals, investors, etc. with the view that it serves as a hedge against inflation, currency crises and any other form of risks. The production of gold and its uses increased so much as continued economic, political and social uncertainty around the globe fueled the demand for gold as a high-quality liquid asset (World gold council 2016). Production of gold over the years have been identified as; 


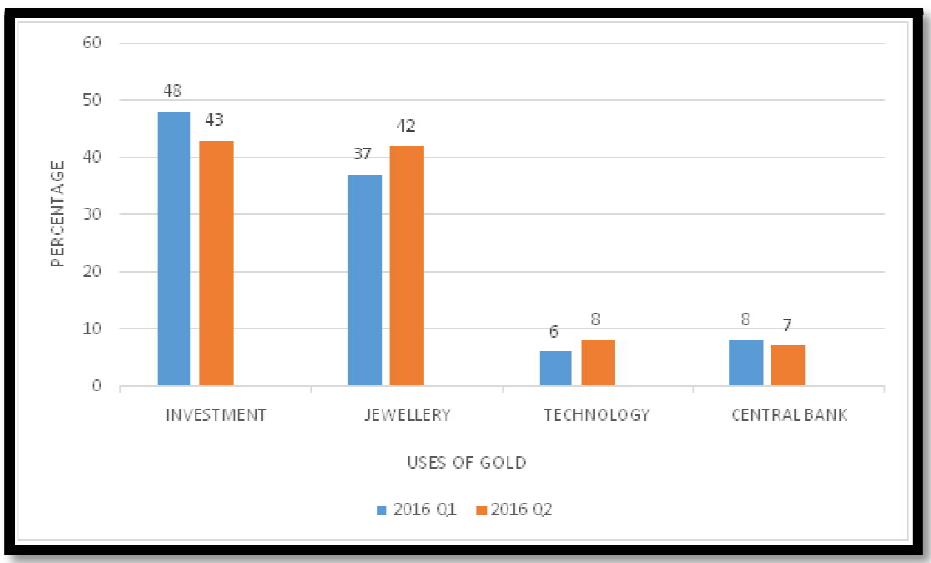

Figure 1: Trends of World Demand for Gold

The figure above shows the various uses of gold demand. Demand for investment purposes decreased from $48 \%$ in the first quarter to $43 \%$ in the second quarter signifying a 5\% decrease. The use demand increased from $37 \%$ in the first quarter of 2016 to $42 \%$ in the second quarter and technology use also increased from $6 \%$ to $8 \%$. Central Bank and other investment also decreased by $1 \%$.

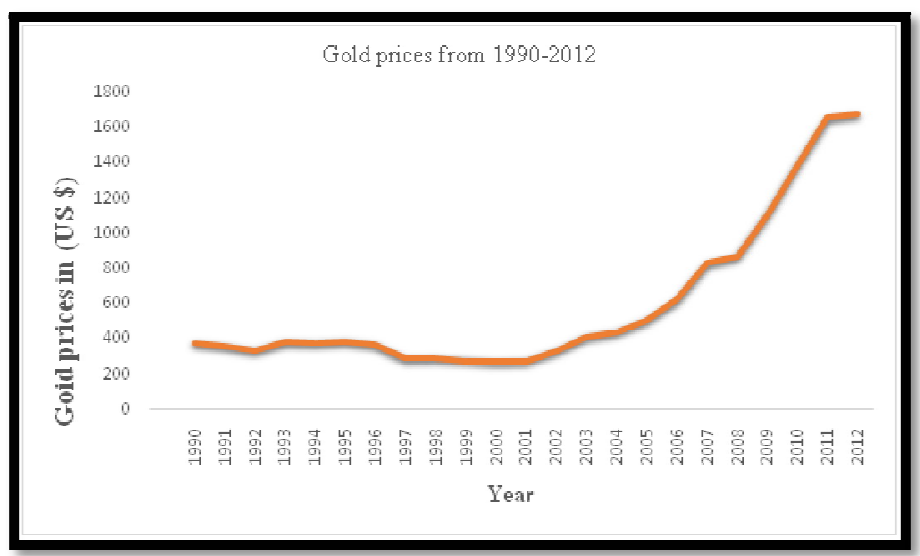

Figure 2: Gold Prices

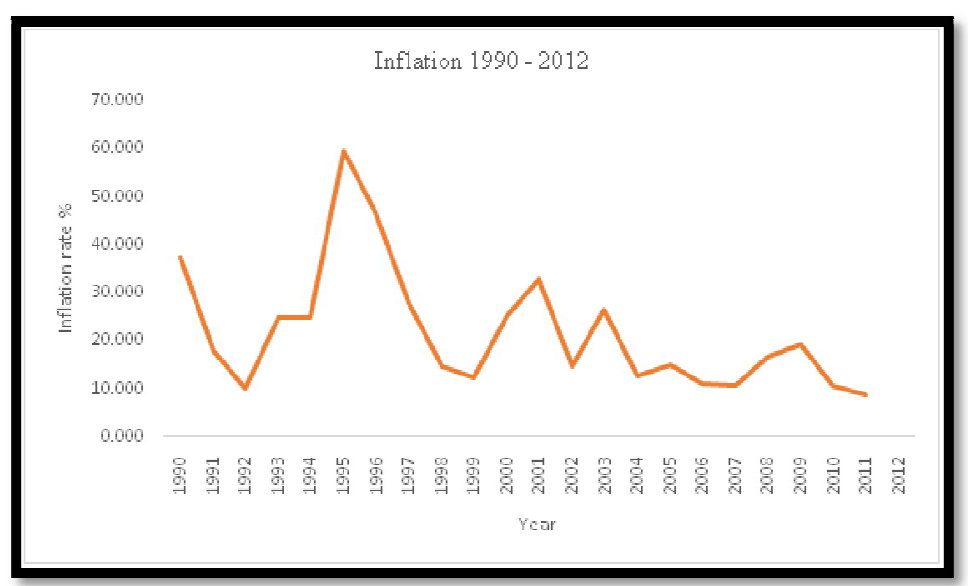

Figure 3: Inflation Rate 


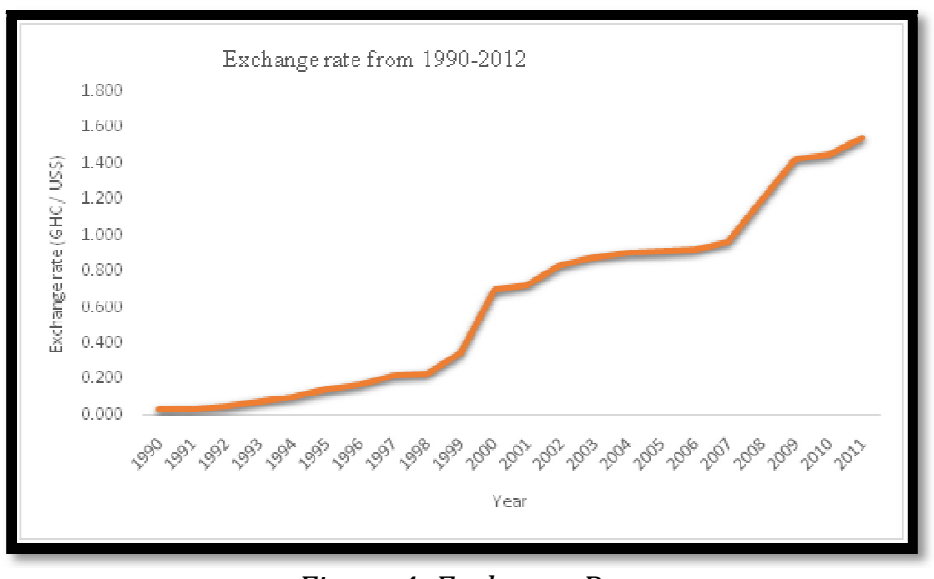

Figure 4: Exchange Rate

Using data spanning 1990-2012, it can be observed fromFigure 2 that even though there were some few fluctuations, gold prices remained stable from 1990 - 2002. Steadily, the prices began to increase from 2003 and between 2007 and 2008 where there was a sharp increase in price afterwards. From Figure 3 we can see that the trend of inflation has not been stable, although there was a sharp rise in consumer price from 1995 (59.46\%), it dropped to 12\% in 1999. The time trend of Ghana cedi-US dollar exchange rate has been shown in Figure 4. Looking at the data, there have been continuous depreciation against the dollar and in the year 2000 the depreciation was marked by a fall and rise in gold prices in inflation respectively.

\subsubsection{Exchange Rate}

Exchange rate is the value of a country's currency against another country's currency on the stock market. The stock market is the market where equity is raised by various companies. Investors may invest in economy with a high currency value in order gain more returns. (Ibrahim, 2018) reveals that investors attitude is not towards returns only but also towards risk. Ghana has experienced a lot of exchange rate fluctuation. Exchange rate volatility in Ghana is caused by output in the short run, significantly influenced by government expenditure growth, money supply, terms of trade stock, FDI, flows and domestic output movements in the long run (Alagidede and Ibrahim, 2016). Ghana has gone several episodes and policies aimed at stabilizing exchange rate but rather volatile nature of it has left policy makers beset with quandary as to what factor significantly drive currency movements (Alagidede and Ibrahim,2017). The cedi weight of depreciation stabilized in 2007 where a new currency was introduced and the new GHc 1 was equal to US \$ 1 , signifying the strength in the cedi. A country's currency is said to be strong depending on the amount of currency needed to buy another currency. The strength of the cedi from the year 2007 pared way for a lot of investors into the country, however from the year 2013 downwards the cedi has depreciated at a very increasing rate such that currently, GHc 4.92 equals US \$ 1. Moreover, 1 euro equals GHc 5.94, a pound sterling equals GHc 6.81. From the mention points, it can clearly be seen that the value of the cedi has been faced with some fluctuations leaving investors, individuals and policy makers with certain form of risks which makes the unsecured. There is therefore the need for investors to identify an asset that can provide a safe hedge or serve as a hedge against the currency crises in Ghana. Since continues fluctuations in the exchange rate disrupt planning and is not good for economic growth.

\subsubsection{Inflation}

For the purpose of this study inflation is the supply of money in an economy which result in having more money competing for the relatively same amount of goods and services thus pushing up prices. Adu and Marbuah, (2011) employing the ARDL approach to integration, result confirm the significant real output, nominal exchange rate, broad money supply, nominal interest rate and fiscal deficit in explaining inflation in Ghana. Their study reveals that inflation is highly elastic to monetary supply in the long run in Ghana and that money plays an important role in the inflation process in Ghana. CEPA reveals that the excessive growth in money supply has been a major cause of high inflation in Ghana. Government borrowing to finance persistent and rising fiscal deficits and the accumulation of the international reserves by the bank of Ghana. CEPA (2009). There existsa higher significance relationship between inflation and output growth and as such, any policy which increases output is likely to favorable, there should be vigorously persuade (Adu and Marbuah, 2011). Inflation can therefore be seen as a factor affecting economic growth. High level of inflation has a negative impact in a country's economic growth.

\subsubsection{Trade Openness}

Trade openness is considered as an increase the size of a country's traded sectors in relations to output. There exits relationship between trade openness and economic growth. Trade can directly increase per capita income when countries specialize in production goods in which they have comparative advantage but it can also indirectly encourage development via channels such as technology, transfer, product diversity, increasing scale economics, efficient allocation and distribution of resources within the economy and interaction with trading partners. Trade openness affect economic growth, however some factors which affect trade openness is seen as inflation, exchange rate, investment, etc. 


\subsubsection{Financial Crises}

Financial crises are described as any of a broad variety of situation in which some financial assets suddenly loss a large part of its nominal value. It can cause investors to withdraw or sell off their asset from financial institution if left unchecked, a crisis can cause an economy to go into a recession, (Kenton, 2018).

\subsubsection{GDP Per Capita}

GDP per capita is a measure of a country's economic output that accounts for its number of people. It is measured as GDP over the population. GDP per capita between countries is compared using the purchasing power parity (PPP) GDP, on order to create equality between countries by comparing the basket of goods. The PPP valves a country's currency by what it can buy in that country, not just by its valve as measured by exchange rates, (Amadeo, 2018). A country's per capita GDP shows how well an economy is doing and the quality of life of individuals in an economy. A country whose GDP per capita is strong and high gives the population a good standard of living, thereby promoting economic growth and attracting investors. The above mentioned are all factors which influence economics growth of an economy, therefore due to uncertainties or risks that is likely to affect an economy or investors, there is the need to study or examine an asset that can serve as a safe haven to investors. Therefore, our study to examine whether gold can provide a hedge against investor's inflations and exchange rate movement in Ghana is an important study for policymakers, investors and governments.

\subsection{Theoretical Literature}

Inflation risk is one of the main concerns of investors, a lot of studies have revealed that assets or stocks are potential hedge against inflation. Fisher (1930) states that the expected nominal interest rate is equivalent to the sum of the expected real interest rate and the expected inflation rate and also that the real and monetary sectors of the economy are largely independent. Therefore, the expected inflation should be fully reflected into the expected nominal interest rate. The theory is generalized to nominal return on any asset, which should move one-for-one with expected inflation (Fama and Schwert, 1977). The proposition can be expressed as;

$R t=[E t-1(r t)]+[E t-1(\pi t)]+\mu t$

Where Rtis the nominal return, $[E t-1(r t)]$ is the expected real return, $[E t-1(\pi t)]$ is the expected rate of inflation while $\mu t$ is the error term.

By relying on the independence of the expected real return and expected inflation rate and following from the rational expectations, the expected $[E t-1(\pi t)]$ and $(\pi t)$ actual inflation rate; and the expected nominal $[E t-1(r t)]$ and $(r t)$ actual return may vary by a stationary zero mean forecast error. These can be expressed respectively as:

$\pi t=[E t-1(\pi t)]+\delta 1 t$

$r t=[E t-1(r t)]+\delta 2 t(2.3)$

Where $\delta 1 t$ and $\delta 2 t$ represent stationary zero mean forecast errors.

By putting equations (2.2) and (2.3) into equation (2.1), we get;

$R t=r t+\pi t+\Omega$

Where $\Omega=\mu t-\delta 1 t-\delta 2 t$.By way of regressing the nominal return on inflation, Fisher's hypothesis can loosely be expressed as:

$R t=\alpha i+\beta i \pi t+\mu t$

Where $R t, \pi t$ and $\mu t a r e$ as previously defined; $\alpha$ iis the expected real rate of stock returns; ßimeasures changes in Rtresulting from changes in $\pi t$.

\subsection{Empirical Literature}

Long et al, (2013), investigating properties of gold of Vietnam, researching formidable records in 1980's - 1990's. Their findings reveal that, gold provides a complete hedge against both the ex post and ex ante inflation. Their findings support the fisher hypothesis that, nominal gold returns move in a one-for-one correspondence with expected inflation.

Wang, Lee and Thi, (2011) study reveals that gold prices increase along with inflation and as a result provides a hedge against inflation in Japan using data spanning 1979 to 2009, Baur and McDermot (2010), shows that gold is both a hedge and a safe haven for major European stock markets and the US but not for Australia, Canada, Japan and large emerging markets such as the BRIC. They find that, gold is a strong hedge and safe haven for most developed markets during the peak of a financial crisis.

Levin and Wright (2006), study on gold is consistent with the widely held belief that there is a longs term one-forone relationship between the price of gold and the general price level. Their findings reveal that changes in gold prices is positively related to inflation, inflation volatility and a negative relationship is found with regard to the US dollar exchange rate and gold rate.

Using VECM and data spanning January 1995 - November 2006, Ozturck and Acikalin, (2008) find that there is a long run relationship between gold prices, inflation and the Turkish Lira and US exchange rate. Dee et al, (2013) study on the topic revealed that gold cannot serve as a hedge against inflation and stock always or at every time, but rather it serves as a hedge only in the long run. Dempster and Artigas, 2010 studies found that, gold serves as a hedge and a long-term strategic asset, therefore central banks are encouraged to hold gold and investors should also use it. Chua and Woodward (1982) research on gold as an inflation reveals that, gold serves as a hedge against inflation if changes in the returns in gold investment affect changes in the general price level. Their results discover that; gold can serve as a hedge against inflation for the US but not every other country. Using the co-integration approach with data spanning 1945- 2006, Worthington and Pahlavani (2007) provides a strong evidence of a co-integrating relationship between gold and inflation. 
Their results are also consistent with the precious findings that both direct and indirect gold investment can serve as a hedge against inflation.

Using monthly gold price data spanning 1976 - 1999 and employing co-integration regression techniques, Ghosh et al finds that the price of gold rises over time at the general rate of inflation and therefore can be an effective hedge against inflation. However, they find that for the short term, the nominal gold price is heavily dominated by short run changes in the gold leads rate, real interest rate, convenience yield, default risk, the co-variance of gold returns with other asset and exchange rate. Their findings therefore show that gold can hedge against inflation in the long run but not the short run. Using the time variant, time invariant and co-integration framework over the period 1791-2010, Bampins and Panagiotidis, (2015) researched on whether gold can serve as a hedge against inflation. Their result reveals that gold was able to hedge expected and core CPI. The strength of the result will improve if it allowed to vary long term dynamic over time. Erb and Harvey, (2013) using a data from 1975 - 2011, examines whether gold serve as an inflation hedge. Their findings reveal little evidence that gold has been an effective hedge whether measured in the short term or long term. The price of gold at the time of investigation was high compared to history. They checked in three ways to see whether gold serves as a hedge against inflation in the short run. They first examined if the price of gold and the CPI moved proportionally. They discovered that inflation drive price of gold and the actual price of gold were rarely equal. They again investigate the historical fluctuation in real price of gold that the inflation adjusted price of gold and finds that the real historical price of gold has been quiet volatile. Their results show that there is no relation between gold price and unexpected inflation.

Lastly, they check whether gold serve as an inflation in the long run by checking if the ten-year nominal and real gold returns move in the same direction as the ten-year CPI inflation rate. They find that gold does not serve as an inflation hedge in the long run. Thus, looking at Erb and Harvey (2013), their findings show that gold does not serve as an inflation hedge both in the short and long run.

Capie et al. (2005), found that gold had been a hedge against the dollar using data spanning January 1971 February 2004. They state that, unlike money, gold cannot be produced by authorities thus, gold should be able to hedge currency risk because it is not affected by changes in money supply.

Joy (2011) tested if gold was a hedge against the US dollar using a multivariate GARCH model of dynamic conditional correlations for several major dollars paired exchange rate. Using data spanning January 1986 to August 2018 that is 23 years, he finds that gold has served as a hedge against the US dollar and also in recent years' gold has served increasingly effective hedge against currency risk associated with e US dollar.

Reboredo (2013), using the COPULAS as a way to characterize average and stream market dependent between gold and US dollar, find that gold acts as a hedge against the US dollar by using weekly data over the period January 2000 to September 2012. He finds positive and significant results between gold and the US dollar when testing his method on a broad set of currency.

The above empirical studies conclude that; gold does not serve as an inflation hedge in the short-run. Majority of the existing studies reveal that gold serve as a hedge against inflation in the long-run, however, Erb and Harvey (2013) findings depicts that, gold does not serve as an inflationary hedge in the long-run, making the existing findings inconclusive. The empirical studies also show that gold can act as a good currency hedge while others also show that it varies over time.

\subsection{Conclusion}

This chapter reveals the existing findings and studies made on the topic can gold serve as a hedge against inflation and exchange rate movement. The paper provides the different views of researchers on the long run and short run of the hedging ability of gold against inflation and exchange rate volatility. The various findings are inconclusive. The results show that, gold does not serve as an inflation hedge in the short run, however, there are some which are of the view that gold serves as an inflationary hedge in the long run while others do not see it as such. The chapter reviews the various trends in gold production, inflation and exchange rate movement across the globe and also uses already existing findings on the topic.

\section{Methodology}

\subsection{Introduction}

This chapter discusses the data issues and also addresses the empirical strategy. It describes the various methods used to collect the data. This chapter also discusses the type of model used in analyzing the data collected.

\subsection{Scope of the Study}

This study seeks to examine the nature of the gold market and its ability to hedge against inflation and exchange rate in Ghana. The study uses the time series data on the gold market and the foreign exchange market, providing information on gold prices, exchange rate, inflation, trade openness and GDP per capita. The data used spans 1990-2012 and uses the annual time series data on the gold and foreign exchange market. The study uses the Ghana cedi (GHc) and the US dollar \$ to assess the foreign exchange market.

\subsection{Data Source}

The study makes use of secondary data. This is because in terms of collecting data it uses less time and it is easily assessable. The study uses data provided by the Bank of Ghana, stock exchange market and other sources. It uses the 
monthly time series data provided by the Bank of Ghana on the cedi dollar exchange rate. It also uses data on the prices of gold on the gold market and inflation using the consumer price index.

\subsection{Data Description}

This section of the study describes the various variables.

\section{$\underline{3.4 .1 \text {.Gold Returns }}$}

The study uses annual data on gold prices. Gold returns is proxied by gold prices. For the purpose of this study, the data span for the gold prices is from January 1990 to December 2012. Gold prices are used to proxy gold returns because it keeps record of the trend in the performance of gold, its sales and uses over time.

\subsubsection{Exchange Rate}

Exchange rate refers to the amount of one currency needed to buy a unit of another currency, for the purpose of this study, exchange rate is proxy using the Ghana cedi against the US dollar. The Ghana cedi (GHc) is the currency used in Ghana and the US dollar (\$) is the currency used in the United State of America. GHc / US\$ signifies the amount of Ghanaian cedi needed to buy a unit of the US dollar. Currently, GHc 4.92 is equal to U\$, this means that GHc 4.92 is needed to buy US\$1.

\subsubsection{Inflation}

Inflation is the expansion in the supply of money which results in having more currency competing for the same amount of goods and services, thus pushing up prices. For the purpose of this study, inflation will be proxied using the consumer price index (CPI). The CPI is mostly used as an economic indicator and also used to measure inflation. It acts as a guide to make informed decision about the economy by providing government and business about changes in prices in an economy.

\subsubsection{Economic Growth}

Economic growth or real output is the increase in the inflation adjusted market value of the goods and services produced by an economy over time. Economic growth will be proxied using the GDP per capita. GDP per capita refers to a country's gross domestic product (GDP) per person and it is obtained by dividing its GDP for a period by its average population for the year. GDP per capita is a good indicator of the change in the country's living standard over time. Per capita GDP uses the annual data.

\subsection{Empirical Strategy}

Gold return is a function of some independent variables, where gold is the dependent variable.

$G R_{t}=\mathrm{f}\left(E X R_{t}, I N F_{t}, F C_{t}, T O_{t}, G R O_{t}\right)$

This model talks about the empirical variables discussing which variable is dependent and independent. While gold is the dependent variable, exchange rate, inflation, financial crises, trade openness and Economic growth (proxied by GDP per capita) are the independent variables, where:

GR represents Gold Returns, t represents the time index, EXR represents Exchange rate, INF represents Inflation, TO represents Trade Openness, FC represents Financial Crises and GRO represents Economic growth proxied by GDP per capita. The ' $t$ ' is the time index and ranges from 1990-2012.

$G R_{t}=q_{0}+q_{1} E X R_{t}+\epsilon_{t}$

$G R_{t}=q_{0}+q_{1} E X R_{t}+q_{2} I N F_{t}+\epsilon_{t} 3.3$

$G R_{t}=q_{0}+q_{1} E X R_{t}+q_{2} I N F_{t}+q_{3} F C_{t}+\epsilon_{t}$

$G R_{t}=q_{0}+q_{1} E X R_{t}+q_{2} I N F_{t}+q_{3} F C_{t}+q_{4} T O_{t}+\epsilon_{t}$

$G R_{t}=q_{0}+d_{1} E X R_{t}+d_{2} I N F_{t}+d_{3} F C_{t}+d_{4} T O_{t}+d_{5} G R O_{t}+\epsilon_{t}$

From the equations above $\epsilon_{t}$ is the error term and it is assumed to be independent. The other variables maintain their definition. The co-efficient attached to the various variables shows their elasticity with gold returns. $q_{0}$ is Constant, $q_{1}$ is the co-efficient of exchange rate and it shows the elasticity of gold returns with exchange rate. This means that $q_{1}$ measures the responsiveness of gold prices with respect to the changes in exchange rate. $\mathfrak{d}_{2}$, the co-efficient of inflation shows the elasticity of gold returns with respect to inflation. It measures the responsiveness of gold prices to changes in the general price level. $\mathcal{d}_{3}$ : The co-efficient of financial crises shows the elasticity of gold returns with respect with financial crises. It measures the responsiveness of gold prices to changes in the financial market $d_{4}$.The co-efficient of trade openness shows the elasticity of gold returns with respect to trade openness. It measures the responsiveness of gold prices to changes in the trade openness. $d_{5}$.The co efficient of Economic growth represents the elasticity of gold returns with respect to Economic growth. It measures the responsiveness of gold prices to changes in Economic Growth. If the coefficient $\left(\mathfrak{d}_{1}\right)$ is $>0$, then it positively affects gold returns otherwise it is negative and it is similar to the co-efficient of the other variables. Therefore, if exchange rate volatility shows a positive impact on gold returns, then $\left(\mathbb{d}_{1}\right)$ is $>0$ otherwise $<$ 0 , if inflation shows a positive impact on gold return then $\left(\mathfrak{d}_{2}\right)$ is $>0$ otherwise is $<0$. Therefore, if financial crises show a positive impact on gold returns then $\left(\mathfrak{d}_{3}\right)$ is $>0$ otherwise $<0$. In the same way, if trade openness shows a positive impact on gold returns then $\left(\mathfrak{d}_{4}\right)$ is $>0$ otherwise $<0$. Lastly, if the co-efficient $\left(\mathfrak{d}_{5}\right)$ is $>0$, then it positively affects gold returns otherwise it is negative. Therefore, if economic growth shows a positive impact on gold returns then, $\left(\mathfrak{d}_{5}\right)$ is $>0$ otherwise 
is $<0$. It can therefore be said that, if gold prices rise as any of the independent variables rises, then the co-efficient of that variable is $>0$, otherwise it is $<0$.

\subsection{Conclusion}

This chapter estimates the equations using the Ordinary Least Squares (OLS). It adopted appropriate research methodologies to study gold investment in the gold market, the stock exchange market and the Ghanaian economy. The appropriate methodology and data use helped bring out right findings in this study.

\section{Findings and Discussions}

\subsection{Introduction}

This chapter discusses about the findings of the study. It is divided into two parts and discusses the descriptive statistics and empirical findings. The chapter analyses the historical data and consider in details the findings associated with objective of the study.

\subsection{Descriptive Statistics}

This is used to measure and summarize continuous data. It discusses the descriptive statistics of the result in addition to the correlation coefficient. It summarizes large volumes of data in statistical table of mean, median, standard deviation, coefficient of variation, skewness, kurtosis, minimum, maximum and observation.

\begin{tabular}{|c|c|c|c|c|c|c|}
\hline & GR & INF & EXR & FC & GRO & TO \\
\hline Mean & 602.529 & 21.192 & .686 & .260 & 1046.649 & 77.094 \\
\hline Median & 383.6 & 16.522 & .729 & 0 & 982.945 & 75.378 \\
\hline St. Deviation & 442.701 & 13.022 & .560 & .448 & 199.751 & 20.868 \\
\hline $\begin{array}{c}\text { Coefficient of } \\
\text { variation }\end{array}$ & 0.734 & 0.614 & 0.816 & 1.723 & 0.190 & 0.270 \\
\hline Skewness & 1.494 & 1.411 & .433 & 1.089 & 1.105 & .013 \\
\hline Kurtosis & 3.868 & 4.591 & 2.087 & 2.186 & 3.426 & 2.138 \\
\hline Minimum & 271.5 & 7.126 & .034 & 0 & 823.592 & 42.488 \\
\hline Maximum & 1678.82 & 59.462 & 1.879 & 1 & 1558.476 & 116.048 \\
\hline Observations & 23 & 23 & 23 & 23 & 23 & 23 \\
\hline
\end{tabular}

Table 1: Descriptive Statistics

Notes: $G R=$ Gold Returns, $I N F=$ Inflation, EXR = Exchange Rate, $F C=$ Financial Crises, GRO = GDP per Capita and TO = Trade Openness

From Table 1 above, gold returns have a mean of 602.529 with a standard deviation of $442.701 \%$. It is observed that, the mean of inflation is $21.192 \%$ with a standard deviation of 13.022 . Exchange rate has an average of $0.686 \%$, a standard deviation of $0.560 \%$ and minimum and maximum values of $0.034 \%$ and $1.879 \%$ respectively. The mean value of financial crises is $0.260 \%$ and a standard deviation of $0.448 \%$. Financial crises have the lowest mean value amongst all the other variables. From the observations, GDP per capita has a mean value of $1046.649 \%$ and a standard deviation of $199.751 \%$. Trade openness also has a mean value of $77.094 \%$ and a standard deviation of $20.868 \%$. By computing for the coefficient of variation which is calculated as a ratio of standard deviation to mean to examine the volatility of the variables, it is revealed that financial crises are the most volatile with a coefficient of variation of 1.723 followed by exchange rate with 0.816 . Gold returns, inflation and trade openness show a volatility of $0.734,0.614$ and 0.270 respectively. GDP per capita is the least volatile among the variables with 0.190 . Given the positive skewness, it can be said that all the variables are skewed to the right. For kurtosis, if the value is equal to 3 then it can be said that it has a normal distribution, if the value is greater than 3 then the pattern is Leptokurtic and if the value is less than 3 , it is Platykurtic. From the table (4.1), the empirical distribution of the kurtosis for gold returns, inflation and GDP per capita is greater than 3 , this shows that it is clearly not normally distributed but Leptokurtic. For exchange rate, financial crises and trade openness, none of them is normally distributed but Platykurtic since the values for the kurtosis is less than 3.

\subsection{Correlation co-efficient}

The correlation co-efficient is used to measure how strong a relationship is between two variables. A correlation co-efficient of 1 means that for every positive increase in one variable, will result a positive increase of a fixed proportion in the other. On the other hand, a correlation co-efficient of -1 means that for every positive increase in one variable, there is a negative decrease of a fixed proportion in the other. 


\begin{tabular}{|c|c|c|c|c|c|c|}
\hline & GR & INF & EXR & FC & GRO & TO \\
\hline GR & 1.000 & & & & & \\
\hline INF & -0.447 & 1.000 & & & & \\
\hline EXR & 0.841 & -0.523 & 1.000 & & & \\
\hline FC & 0.897 & -0.420 & 0.786 & 1.000 & & \\
\hline GRO & 0.938 & -0.535 & 0.958 & 0.845 & 1.000 & 1.000 \\
\hline TO & 0.058 & -0.159 & 0.475 & -0.006 & 0.334 & \\
\hline
\end{tabular}

\section{Table 2: Correlation Matrix}

Notes: $G R=$ Gold Returns, $I N F=$ Inflation, EXR = Exchange Rate, FC = Financial Crises, $G R O=G D P$ Per Capita and TO = Trade Openness

Table 2 shows the co-efficient of correlation of gold returns and some independent variables which includes inflation, exchange rate, financial crises, GDP per capita and trade openness. From the results, it is revealed that there exist a positive and insignificant correlation between Gold returns and all the other independent variables except inflation which is negative and significant. Gold returns and GDP per capita, gold returns and financial crises has a higher correlation as compared to the other independent variables. Inflation is negatively correlated with all the other variables.

\subsection{Empirical Findings}

This section presents the empirical findings of the study on the hedging capacity of gold to inflation and exchange rate movements.

\begin{tabular}{|c|c|c|c|c|c|}
\hline & 1 & 2 & 3 & 4 & 5 \\
\hline Constant & $\begin{array}{c}145.945 \\
(81.845) \\
{[1.78]} \\
\{0.089\}\end{array}$ & $\begin{array}{c}155.967 \\
(165.295) \\
{[0.94]} \\
\{0.357\}\end{array}$ & $\begin{array}{c}253.419 \\
(122.456) \\
{[2.07]} \\
\{0.052\}\end{array}$ & $\begin{array}{c}558.902 \\
(181.358) \\
{[3.08]} \\
\{0.006\}\end{array}$ & $\begin{array}{c}-1803.101 \\
(387.513) \\
{[-4.65]} \\
\{0.000\}\end{array}$ \\
\hline EXR & $\begin{array}{c}664.941 \\
(93.168) \\
{[7.14]} \\
\{0.000\}\end{array}$ & $\begin{array}{c}660.813 \\
(112.049) \\
{[5.90]} \\
\{0.000\}\end{array}$ & $\begin{array}{c}280.334 \\
(119.966) \\
{[2.34]} \\
\{0.031\}\end{array}$ & $\begin{array}{c}570.708 \\
(174.431) \\
{[3.27]} \\
\{0.004\}\end{array}$ & $\begin{array}{c}-227.011 \\
(159.887) \\
{[-1.42]} \\
\{0.174\}\end{array}$ \\
\hline INF & & $\begin{array}{c}-.339 \\
(4.820) \\
{[-0.07]} \\
\{0.945\}\end{array}$ & $\begin{array}{c}-.095 \\
(3.510) \\
{[-0.03]} \\
\{0.979\}\end{array}$ & $\begin{array}{c}.968 \\
(3.256) \\
{[0.30]} \\
\{0.770\}\end{array}$ & $\begin{array}{c}2.460 \\
(1.846) \\
{[1.33]} \\
\{0.200\}\end{array}$ \\
\hline FC & & & $\begin{array}{c}608.090 \\
(140.557) \\
{[4.33]} \\
\{0.000\}\end{array}$ & $\begin{array}{c}334.289 \\
(181.394) \\
{[1.84]} \\
\{0.082\}\end{array}$ & $\begin{array}{c}131.214 \\
(106.952) \\
{[1.23]} \\
\{0.237\}\end{array}$ \\
\hline TO & & & & $\begin{array}{l}-5.914 \\
(2.757) \\
{[-2.14]} \\
\{0.046\}\end{array}$ & $\begin{array}{c}-4.171 \\
(1.575) \\
{[-2.65]} \\
\{0.017\}\end{array}$ \\
\hline GRO & & & & & $\begin{array}{c}2.672 \\
(.422) \\
{[6.32]} \\
\{0.000\}\end{array}$ \\
\hline \multicolumn{6}{|l|}{ Diagnostics } \\
\hline R-Squared & 0.708 & 0.708 & 0.853 & 0.882 & 0.965 \\
\hline Adj R-Square & 0.694 & 0.679 & 0.829 & 0.856 & 0.954 \\
\hline F-Statistics & 50.94 & 24.26 & 36.74 & 33.93 & 93.82 \\
\hline
\end{tabular}

Table 3: empirical Findings on Hedging Capacity of Gold

Note: Values In (), [] and \{\} Represents Standard Error, T-Test and P-Value Respectively

Critical Values for T-Statistic Are 1\% = $\pm 2.58,5 \%== \pm 1.96$ And $10 \%== \pm 1.64$. Critical Value for 5\% F-Statistic Is 4.5. Gr $=$

Gold Returns; Inf = Inflation; Exr = Exchange Rate; FC = Financial Crises; Gro = Gdp Per Capita And To = Trade Openness

From the empirical findings in Table 3, it can be seen that, the correlation co-efficient of $q_{1}$ is 664.941 in model 1 , this shows a positive relationship between exchange rate and gold returns. An increase in exchange rate will cause an increase in gold returns and a decrease in exchange rate will cause a decrease in gold returns. This means that, a $100 \%$ increase in exchange rate will lead to a $664.941 \%$ increase in gold returns. The computed test statistics ( $t *$ ), 7.14 is greater than the critical value at all levels. Therefore, we reject the null hypothesis, which states that exchange rate does not have any impact on gold returns. Thus, the result is significant at conventional levels. The co-efficient of exchange rate in model 2, 3 and 4 are positive and that shows a positive relationship with gold returns. This means that a $100 \%$ increase in exchange rate in model 2,3 and 4 will result in an increase of $660.813 \%, 280.334 \%$ and $570.708 \%$ respectively in gold 
returns. Also, a decrease in exchange rate will result in a decrease in gold returns. The $t^{*}$ in model 2, 5.90 is greater than the critical value at all levels. Therefore, we reject the null hypothesis which states that exchange rate does not have any impact on gold returns. In model 3, the $t^{*}$ is 2.34 and is significant at $5 \%$ and $10 \%$ significant levels. In model 4 , the $t^{*} 3.27$ is greater than the critical values revealing that, it is significant at conventional levels. In model 5 , the co-efficient exchange rate is -227.011 which shows that a $100 \%$ increase in exchange rate will lead to a $-227.011 \%$ decrease in gold returns. The $t^{*},-1.42$ is greater than the critical value at $10 \%$ significant level. Therefore, we reject the null hypothesis since the $\left|t^{*}\right|$ $>|t c v|$. For inflation, from the models, it can be observed that, it has a negative relationship with gold returns in model 2 and model 3, but has a positive relationship with gold returns in model 4 and 5 . This means that, for model 2 and 3 , an increase in inflation will cause a decrease in gold returns and an increase in inflation in model 4 and 5 will lead to an increase in gold returns. Therefore, a 1\% increase in inflation in model 2 and 3 will cause a .339\% and .95\% decrease in gold returns respectively and a 1\% increase in inflation in model 4 and 5 will cause a .968\% and $2.460 \%$ increase in gold returns. The $t^{*}$ for inflation in model 2 and 3 is -0.07 and -0.03 respectively. Since the $t^{*}$ for model 2 and 3 is greater than the critical value at conventional level, we reject the null hypothesis because the result is significant. For models 4 and 5 , the $t^{*}$ is 0.30 and 1.33 respectively and it is less than the critical values at all significant levels, therefore do not reject the null hypothesis because the results are insignificant. For model 3, 4 and 5, the co-efficient of financial crisis is positive signifying a positive relationship between financial crisis and gold returns. This means that, an increase in financial crisis will cause an increase in gold returns. A $100 \%$ increase in financial crisis will lead to a $608.090 \%, 334.289 \%$ and 131.214 $\%$ increase in gold returns in model 3, 4 and 5 respectively. From the computed test statistics for model 3, 4 and 5, the results show 4.33, 1.84 and 1.23 respectively. For model 3 , the $t^{*} 4.33$ is significant at conventional levels therefore we reject the null hypothesis, model 4 has a $t^{*}$ of 1.84 and it is significant at $10 \%$, therefore do not reject the null hypothesis at $1 \%$ and $5 \%$ significant levels and this means that, the results are insignificant at these levels. Trade openness has a coefficient of -5.914 and -4.171 in model 4 and 5 and this signifies a negative relationship between trade openness and gold returns. This means that, an increase in trade openness will lead to a decrease in gold returns. A $1 \%$ increase in trade openness will cause a $-5.914 \%$ decrease in gold returns for model 4 and a $1 \%$ increase will also cause a $-4.171 \%$ decrease in gold returns. The test statistics for model 4 is -2.14 and it is greater than the critical value at $1 \%$ significant level but less than $5 \%$ and $10 \%$ significant levels, therefore reject the null hypothesis at $1 \%$ significant level and this shows that the result is significant at that level. For model 5 , the $t^{*}$ is -2.65 and it is less than the critical values at all levels, therefore do not reject the null hypothesis, implying an insignificant result. Economic growth, proxied by GDP per capita has a positive co-efficient of 2.672 signifying a positive relationship between economic growth and gold returns. This means that an increase in economic growth will result in an increase in gold returns. A $1 \%$ increase in economic growth will lead to a $2.672 \%$ increase in gold returns. The $t^{*}$ shows a result of 6.32 which is greater than the critical values at conventional levels therefore, reject the null hypothesis and this means that the result is significant.

The results in Table 3 above shows that, there exist a positive relationship between gold and inflation where a percentage change in inflation increases gold returns by $0.968 \%$ and $2.460 \%$. Based on the co-efficient, it is revealed that gold can serve as both a perfect and imperfect hedge against inflation. It can therefore be concluded that gold is able to serve as a hedge against inflation and this finding is consistent with Dee et al, (2013), Ghosh et al, (2004) and Dempster and Artigas, (2010). However, the results in model 2 and 3 shows a negative relationship between gold and inflation which means gold does not serve as a hedge which is consistent with the findings of Erb and Harvey, (2013). Based on this result, whether gold serves as a hedge or not against inflation depends on the model used and for that matter is inconclusive on the ability of gold to hedge against inflation contrary to what our study found. The results also reveal that an increase in exchange rate increases gold returns signifying a positive relationship between gold and exchange rate. Based on the coefficients, the results show that gold is able to serve as a perfect hedge against exchange rate movement in Ghana and this is consistent with the findings of Carpie et al, (2005), Joy, (2011) and Reboredo, (2013). The results in model 5 however show that, gold does not serve as a hedge against exchange rate as a percentage increase in exchange rate will decrease gold returns. This result also shows that whether or not gold is a hedge against exchange rate movement is dependent on the model and for that matter is inconclusive on the hedging capacity of gold against exchange rate movement which is also contrary to what our study found.

\subsection{Diagnostic Tests}

For model 1-5, the coefficient of determination $\left(R^{2}\right)$ is $70.8 \%, 70.8 \%, 85.3 \%, 88.2 \%$ and $96.5 \%$ respectively. This means that, about $70.8 \%$ of the changes in the dependent variable for model 1 and 2 can be explained by changes in the independent variable. For model 3, about $85.3 \%$ of the variations in the dependent variable can be explained by variations in the independent variable. About $88.2 \%$ and $96.5 \%$ of the changes in the dependent variable can be explained by changes in the independent variables in model 4 and 5 respectively. After adjusting for the degrees of freedom, the adjusted Rsquared for model $1,2,3,4$ and 5 are $69.4 \%, 67.9 \%, 82.9 \%, 85.6 \%$ and $95.4 \%$ respectively. It is found that about $69.4 \%$, $67.9 \%, 82.9 \%, 85.6 \%$ and $95.4 \%$ of changes in the dependent variable is caused by the changes in the independent variables. The p-value for all models is less than the significant level at all levels therefore we reject the null hypothesis for all models. This means that the results are significant. Multicollinearity shows how the independent variables correlate with each other. It is tested for by using the Variance Inflation factor (VIF) which is calculated as 1 over tolerance and tolerance is calculated as $\left(1-R^{2}\right)$. Using the results from the models in Table 3, the VIF shows a result of 3.425, 3.425, $6.803,8.475$ and 28.571 for model $1,2,3,4$ and 5 respectively. There is multicollinearity if the VIF $>10$ and from the results, model 5 shows a VIF of 28.571, therefore there is multicollinearity in model 5 . The VIF of model 1- 4 is less than $10(\mathrm{VIF}<10)$ and this shows that there is no multicollinearity. 


\subsection{Conclusion and Policy Implication}

From this chapter, the empirical findings reveal that there exists a positive relation between gold returns and exchange rate. Inflation on the other hand has both negative and positive relationship with gold returns. The positive relationship between gold returns and inflation show that gold can serve as a hedge against inflation perfectly and imperfectly. As a result of this, gold investors will not lose much in the case of any inflation. The result for exchange rate also shows that, gold is able to perfectly hedge against any currency depreciation. Again, gold investors tend to benefit more if there is exchange rate depreciation since gold is a perfect hedge against exchange rate movement. The correlation coefficient reveals a positive and insignificant correlation between gold returns and all other independent variables except inflation which is negative and significant. The descriptive statistics shows financial crises as the most volatile followed by exchange rate and with the positive skewness. It can be said that all the variables are skewed to the right. The results from the diagnostic test revealed that, a greater percentage of the changes in the dependent variable is caused by changes in the independent variables which shows the relevance of the result.

\section{Summary of Findings, Recommendations and Conclusion}

\subsection{Introduction}

Chapter five presents the summary of the findings and the conclusions made from the study. It also comprises of the recommendations made or the ability of gold providing hedge against exchange rate and inflation by the group.

\subsection{Summary of the Key Findings and Conclusion}

This section talks about the summary of the key findings identified from the study and the conclusions arrived at.

\subsubsection{Objective One}

The first objective of the study is to document the empirical distribution of gold returns, inflation and exchange rate in Ghana from 1990 - 2012. From the study, the results revealed that exchange rate has been continuously increasing over the years which shows that the Ghana cedi has been depreciating in the years used for the study. The results also revealed inflation experience an increase and decrease over the years. This shows that, over the year's inflation has not been stable but increases and decreases. Gold returns has also been increasing and decreasing over the years. The study therefore shows that gold returns are volatile, that is the prices move up and down. The results also show that the distribution of gold returns, inflation and exchange rate is not normal but it is platykurtic and lepokurtic.

\subsubsection{Objective Two}

The second objective of the study is to determine the hedging capacity of gold against inflationary pressures in Ghana. The data used from 1990-2012 shows that, gold prices increases with respect to pressures from inflation. Model 4 and 5 in Table 3 shows a positive relationship between gold returns and inflation with co-efficient of 0.968 and 2.460 which shows that a $1 \%$ increase in inflation will increase gold returns by $0.968 \%$ and $2.460 \%$ respectively. From the results, it can be seen that gold serves as a perfect and imperfect hedge against inflation but in the long run, since investors tend to purchase gold more as prices rise, it increases gold returns and thus cushions them against inflation. This is because in the case of current depreciation in the Ghana cedi, foreign investors tend to purchase more gold as a result of increase in general prices levels (inflation). As price increases, the prices of gold also increase and as a result every ounce of gold and cedi will rise as a result. Investors get compensated for inflation as a result of more cedi being used to purchase each ounce of gold.

\subsubsection{Objective Three}

The third objective of the study is to examine the hedging capacity of gold returns against exchange rate movements in Ghana. The results show that an increase in exchange rate causes an increase gold returns. Since exchange rate is measured using the cedi per dollar, it shows an increase in exchange rate denoting a depreciation in the cedi. Given the rate of currency depreciation in Ghana, it is likely to affect the demand for gold. The more volatile nature of the Ghanaian cedi causes investors outside to purchase more of gold when the cedi depreciates. Investors within Ghana, which is in the cedi area decrease their demand for gold when the cedi depreciates because the depreciation of the cedi will cause an increase in the price of gold for domestic investors. This is because in the event of a depreciation of the cedi, more cedi would have to be converted by the domestic investors in order to buy an ounce of gold leading to a decrease in the demand for gold. Foreign investors in the dollar area on the other hand will purchase more of gold increasing the gold demand and prices since the prices of gold in the US dollar is relatively lower. These findings reveal that, most of the investors in the gold market are within the dollar area. When the value of cedi depreciates, investors do not want to hold the cedi so they use it to invest in gold. In the event of increase in exchange rate when gold is exported to other country it increases the value of the cedi against the dollar. This means that when gold prices rise, it increases and strengthens the value of the cedi thereby serving as a hedge against exchange rate movement in Ghana.This dissertation used the regression model to identify the hedging capacity of gold serving as a hedge against inflation and exchange rate movement in Ghana using the annual time series data obtained from the Bank of Ghana. It was found that, the ability of gold to serve as a hedgeagainst exchange rate was possible since a fall in the cedi makes investors within Ghana demand for gold become lower and investors within the dollar zone increase their demand for gold and as a result increases the dollar price of gold. Gold is also a hedge against inflation because the fall in the value of the cedi against the dollar causes prices to rise and as they rise increase the prices of gold. As a result, investing in gold at the period hedges investors against the currency risks they 
encounter, this means investing in gold at the inflationary period increases their returns since the price increase will cause more cedi to be used in purchasing one ounce of gold and they will be compensated for the inflation in the long run.

\subsection{Policy Recommendation}

Following the empirical findings of our study, we find that gold cannot always serve as hedge against inflation and exchange rate movement but can only serve as a hedge against inflation when it is held for a long period of time. We therefore recommend that, investors should invest more in gold because it is able to serve as a hedge against inflation and exchange rate in Ghana in the long run. This is because an increase in inflation reduces the real value of money and as a result investor seek for other avenues to invest in, in other to preserve the value of the asset and earn additional returns. Gold is therefore a good avenue to invest since it can protect investors against unexpected inflation. We also recommend that, policy makers should encourage investment in gold so that in the case of a fall in the cedi value against the dollar, the gold returns will cushion investors against the currency risks.

\subsection{Research Contribution to Existing Literature}

This study contributes to existing literature by testing to see whether gold can serve as hedge against inflation and exchange rate movements in the long run or short run in Ghana. It was found that gold can be able to serve as an inflationary and exchange rate hedge when it is held in the long run.

\subsection{Further Research Areas}

For further studies, the time varying coefficient in return equation method and the ARDL bounds testing approach should be used to determine the relationship between the variables gold, inflation and exchange rate. Further studies can also be made to determine the ability of gold to serve as a diversifier that can mitigate losses in times of market stress for investors.

\section{References}

i. Alagidede, P., and Ibrahim, M., (2016), 'On the causes and effect of exchange rate volatility on economic growth' Evidence from Ghana.

ii. Amadeo,K.,(2018), Gross Domestic Product and how it affects you.

iii. Bampinas, G., and Theodore, P., (2015), Are gold and silver a hedge against inflation? A two-century perspective, Review of Financial Analysis, Elsevier, Vol.41(C), pages 267-276.

iv. Baur, D., and McDermott, T., (2010), Is gold a safe haven? International evidence, - Journal of Banking and Finance, Vol.34, Issue 8, pp.1886-1898.

v. Carpie, F., Mills, T.C., and Wood, G., (2005), 'Gold as a hedge against the dollar,' Journal of International Financial Markets, Institutions and Money, Vol.15, No.4, pp.343-352.

vi. Chua, J.H., and Woodward, R.S., (1982), 'gold as an inflation hedge: a comparative study of six major industrial countries; Journal of business finance and accounting, Vol. 9, No 2, pp., 191-197.

vii. Dee, J., Li, L., and Zheng, Z., (2013), Is gold a hedge or a safe haven? Evidence from inflation and stock market, International journal of Development and Sustainability, Vol.2, No.1, pp. 12-27.

viii. Erb, C.B., and Harvey, C.R., (2013), The Golden Dilemma, Financial Analysts Journal, Vol.69, No.4, pp.10-42.

ix. Fama, E.F., and Schwert, G.W., (1977),' Asset returns and inflation,' Journal of Financial Economics, Vol.5, No.2, pp. 115-146.

x. Fisher, (1930), The theory of interest MacMillan, New York.

xi. Adu, G., and Marbuah, G., (2011), Determination of inflation in Ghana: An empirical investigation, - South African Journal of Economics, Vol.79, Issue 3, pp. 251-269.

xii. Ghosh, D., Levin, E.J., MacMillan, D., and Wright, R.E., (2004), 'gold as an inflation hedge? Studies in Economics and finance, Vol. 22, No.1 pp.1-25.

xiii. Ibrahim, M., and Alagidede, P., (2017),'Financial sector development, economic volatility and shocks in subSaharan Africa,'physica A: Statistical Mechanics and its Applications, Elsevier, vol.484 (C), pages 66-81.

xiv. Ibrahim, M., and Musah, A., (2015),' can gold investment provide a hedge against inflation and exchange rate? International Journal Economics and Business Research Vol.10 No.2, pp.148-166.

xv. Kaufmann, T.,and Winters, R., (1989), The price of gold: A simple model, Resources policy, Vol.19 pp. 309-318.

xvi. Kolluri, B.R., (1981), Gold as a Hedge against inflation; An empirical investigation, Quarterly review of Economics and Business, Vol.21 pp13-24.

xvii. Levin, E. J., and Wright, R.E., (2006), 'Short-term and long-run determinants of the price of gold; Research study, No.2, pp169-210.

xviii. Long, H.L., De Ceuster, M.J.K., Annaert, J., and Amonhaemanon, D., (2013),'Gold as a hedge against inflation; the Vietnamese case; Procedia Economics and Finance, Vol.5, pp.502-511.

xix. Mark, J., (2011), Gold and the US dollar, Hedge or haven? Finance Research Letters Vol.8, Issue 3, pp.120-131.

xx. Ozturk, F., and Acikalin, S., (2008),' Is gold a safe hedge against Turkish Lira? South East European, -Journal of Economics and Business, Vol.3, No.1, pp.35-40.

xxi. Reboredo, J., (2013), Is gold a hedge or safe haven against oil price movement? Resources Policy: Vol.38, Issue 2, pp. 10-137.

xxii. Worthington, A.C., and Pahlavani, M., (2007), Gold investment as an inflation hedge: Cointegration evidence with allowance for Endogenous Structural breaks, Applied Financial Economics letters, Vol.3, pp. 259-262. 